\title{
ESTRATÉGIAS ORGANIZACIONAIS, 0 DIFÍCIL PROCESSO DE TOMADA DE DECISÃO: CASO DE ENSINO DA INDÚSTRIA TÊXTIL
}

ORGANIZATIONAL STRATEGIES, THE DIFFICULT DECISION-MAKING: INDUSTRY EDUCATION EVENT TEXTILE

\section{Fernando Eduardo Cardoso \\ fernandoecardoso@hotmail.com \\ Universidade do Vale do Itajaí (UNIVALI), Itajaí/SC, BRASIL}

\section{Sidnei Vieira Marinho}

sidnei@univali.br

Universidade do Vale do Itajaí (UNIVALI), Itajaí/SC, BRASIL

\section{Anete Alberton}

anete@univali.br

Universidade do Vale do Itajaí (UNIVALI), Itajaí/SC, BRASIL

\section{Resumo}

O caso tem por objetivo levar os alunos a vivenciar decisões relacionadas ao processo de tomada de decisão organizacional, ao discutir as estratégias adotadas pela empresa com base no método clássico de formulação da estratégia descrito por Porter. O caso foi desenvolvido para ser usado em programas de pós-graduação para discussão do processo de formulação das estratégias organizacionais e processo de reposicionamento da marca. Existe a possibilidade de adaptar as questões de análise para ser usado por alunos da graduação nas disciplinas de modelos de gestão. As informações descritas neste caso de ensino foram obtidas por meio de observação participante, visita ao museu da empresa, consulta a sites da empresa e da BM\&FBovespa e entrevistas com funcionários de diversos níveis hierárquicos. A proposta é fazer com que os estudantes se coloquem no lugar dos acionistas da empresa, para analisar as estratégias tomadas pela empresa, analisando cada estratégia dentro da roda de estratégia competitiva de Porter.

Palavras-chave: Estratégia. Indústria Têxtil. Tomada de Decisão.

\begin{abstract}
The event aims to lead students to experience decisions related to the decision-making process of organizational strategies, discussing the strategies adopted by the company based on the classic method of formulating the strategy described by Porter. The case is designed to be used in graduate programs for discussion of the strategy formulation process; organizational strategies and brand repositioning process. If adapt the questions can be used to grade students in management models of disciplines. The information described in this teaching case were obtained through participant observation, visit the company's museum, and query the company's sites and BM\&FBovespa and interviews with officials of various levels of the organization. The proposal is to get students to put in place the company's shareholders, to analyze the strategies adopted by the company, analyzing each strategy within the competitive strategy wheel Porter.
\end{abstract}

Keywords: Strategy. Textile Industry. Decision-making. 


\section{Introdução}

É uma manhã de verão, na agenda de Eduardo, acionista da empresa, havia apenas uma reunião na filial da cidade de São Paulo. Eduardo estava apreensivo, sabia que nesta reunião seriam apresentadas as novas estratégias da empresa, e seus objetivos para o próximo quadriênio.

A empresa trabalho com quatro marcas de produtos para vestuário, atendendo diversas classes sociais e públicos diferentes. A marca "P" é a principal parca da empresa, a responsável pelo maior volume de venda, e que atende ao público adulto de todas as classes sociais. A marca "X", são vestuários para publica infantil, de todas as classes sociais. O produto de vestuário da marca "Y", atende ao publica infantil da classe "A" e "B". Por fim a quart marca trabalhada pela empresa a marca " $Z$ " atende ao público jovem, da classe social "A" e "B".

Já na reunião, foi apresentado aos acionistas um plano estratégico de crescimento para o quadriênio (20072010). Tal estratégia de crescimento priorizava o foco na força da principal marca da empresa, a marca "P" e na estrutura de varejo, com o objetivo de aumentar a participação no mercado nacional. As principais diretrizes da estratégia podem ser sumarizadas nos seguintes pontos: (i) reposicionar a marca da empresa como moda acessível; (ii) aumentar a oferta de crédito na rede de lojas Store, por meio da operação do cartão de crédito; (iii) expandir e fortalecer a rede de lojas Store (franqueada e loja própria) e; (iv) incrementar as vendas no varejo multimarcas.

Eduardo pensou...

- Conseguiremos este crescimento com as estratégias apresentadas? As pesquisas realizadas pela empresa mostram que ela tem potencial de crescimento.

A empresa aposta na valorização das marcas, reduzindo o número das marcas comercializadas, concentrandose apenas nas próprias. A empresa tinha a licença de marcas conhecidas nacional e internacionalmente e optou estrategicamente em descontinuar, visto que, mesmo com uma venda muito boa dos produtos, proporcionava uma margem de lucro muito baixa, exigindo um capital de giro muito alto.

\section{Como tudo começou....}

A história da indústria, há mais de um século, une-se de forma inseparável à história de uma família de imigrantes alemães que, como tantas outras vieram a procurar novas oportunidades no Novo Mundo e acabou por escrever importante capítulo do desenvolvimento do país, em especial do estado de Santa Catarina.

Quadro 1. História da empresa

\begin{tabular}{|c|c|}
\hline Ano & Histórico \\
\hline 1880 & $\begin{array}{l}\text { Tem início a produção de uma pequena } \\
\text { tecelagem que, embora com recursos } \\
\text { técnicos rudimentares, contava com um } \\
\text { fator decisivo para sua sobrevivência } \\
\text { e crescimento: a família sem exceção, } \\
\text { vinha de uma longa tradição de tecelões, } \\
\text { anterior a } 1686 .\end{array}$ \\
\hline 1893 & $\begin{array}{l}\text { O empreendimento assumiria } \\
\text { juridicamente o porte de empresa. } \\
\text { Enquanto um dos irmãos coordenava } \\
\text { a parte produtiva, o outro vendia o } \\
\text { produto. Em pouco tempo os produtos } \\
\text { confeccionados tornaram-se conhecidos } \\
\text { principalmente por sua qualidade, o que } \\
\text { lhes conferiu na época, medalha de prata } \\
\text { numa exposição. Os produtos encontram } \\
\text { ampla aceitação no mercado em todo } \\
\text { território nacional. }\end{array}$ \\
\hline Década 10 & $\begin{array}{l}\text { Foi adquirida uma fiação completa. } \\
\text { Isto proporcionou independência do } \\
\text { mercado externo de fios de algodão e } \\
\text { uma passagem segura pelos tempos de } \\
\text { recessão ocorridos durante a primeira } \\
\text { guerra mundial. }\end{array}$ \\
\hline Década 20 & $\begin{array}{l}\text { Empresa transformou-se em sociedade } \\
\text { por ações. Nesta década a empresa } \\
\text { inaugura uma filial na cidade de Encano- } \\
\text { SC e outra na cidade de Indaial-SC }\end{array}$ \\
\hline $\begin{array}{l}\text { Década } \\
30-50\end{array}$ & $\begin{array}{l}\text { Marca a fundação de uma cooperativa de } \\
\text { consumo, uma cooperativa de crédito e a } \\
\text { fundação da associação desportiva. }\end{array}$ \\
\hline Década 60 & $\begin{array}{l}\text { A empresa procede a abertura de seu } \\
\text { capital e dá início as exportações, } \\
\text { tornando-se a primeira exportadora de } \\
\text { vestuário do Brasil. Nesta mesma década } \\
\text { a empresa tornando-se uma das maiores } \\
\text { empresas da América Latina. }\end{array}$ \\
\hline Década 70 & $\begin{array}{l}\text { A produção de vestuário especificamente } \\
\text { voltado ao atendimento do público } \\
\text { infantil, onde a empresa lança a sua marca } \\
\text { para o público infantil, expandindo, ainda } \\
\text { mais, o foco neste público }\end{array}$ \\
\hline
\end{tabular}




\begin{tabular}{|c|c|}
\hline Década 80 & $\begin{array}{l}\text { A estrutura da empresa atinge sua } \\
\text { capacidade máxima, produzindo doze } \\
\text { milhões de peças por mês, contando com } \\
\text { mais de } 20.000 \text { colaboradores. A empresa } \\
\text { inaugura uma filial localizada na cidade de } \\
\text { Blumenau. }\end{array}$ \\
\hline Década 90 & $\begin{array}{l}\text { A empresa tinha uma estrutura de capital } \\
\text { fortemente calcada em empréstimos } \\
\text { atrelados ao dólar e, após desvalorização } \\
\text { cambial ocorrida no início de } 1999, \\
\text { a situação financeira da empresa é } \\
\text { adversamente afetada. Para solucionar } \\
\text { tal problema, em dezembro de } 1999, \\
\text { é realizado um aumento de capital, } \\
\text { mediante subscrição pública, no valor de } \\
\text { aproximadamente R\$ } 62,0 \text { milhões, com o } \\
\text { ingresso de novos acionistas. }\end{array}$ \\
\hline 2000-2006 & $\begin{array}{l}\text { A empresa aposta na valorização das } \\
\text { marcas, reduzindo o número das marcas } \\
\text { comercializadas, concentrando-se } \\
\text { apenas nas marcas próprias. A empresa } \\
\text { tinha a licença de marcas conhecidas } \\
\text { nacional e internacionalmente e optou } \\
\text { estrategicamente em descontinuar, visto } \\
\text { que, mesmo com uma venda muito } \\
\text { boa dos produtos, proporcionava uma } \\
\text { margem de lucro muito baixa, exigindo } \\
\text { um capital de giro muito alto. Com esta } \\
\text { estratégia a empresa trocou crescimento } \\
\text { por sustentabilidade, o que estava de } \\
\text { acordo com o momento que a empresa } \\
\text { estava passando. A Empresa retoma a } \\
\text { estratégia de crescimento, contratando } \\
\text { uma empresa de consultoria especializada } \\
\text { em planejamento estratégico. }\end{array}$ \\
\hline 2007-2010 & $\begin{array}{l}\text { A empresa elaborou um plano estratégico } \\
\text { de crescimento para o quadriênio } 2007- \\
\text { 2010. Tal estratégia de crescimento } \\
\text { priorizava o foco na força da marca } \\
\text { principal da empresa, principal vetor de } \\
\text { crescimento da Companhia, e na estrutura } \\
\text { de varejo, com o objetivo aumentar a } \\
\text { participação no mercado nacional. }\end{array}$ \\
\hline $2011-2017$ & $\begin{array}{l}\text { Manteve estratégia expansão, } \\
\text { aproveitando o momento positivo em } \\
\text { que a empresa se encontra para expandir } \\
\text { com a abertura de novas franquias. Para } \\
\text { sobreviver a uma nova crise econômica, } \\
\text { a empresa uma nova campanha de } \\
\text { marketing que promete resgatar suas } \\
\text { origens em uma releitura conectada aos } \\
\text { dias atuais, mantendo-se no mesmo } \\
\text { posicionamento da marca. }\end{array}$ \\
\hline
\end{tabular}

Fonte: $\mathrm{O}$ autor

\section{Existem Problemas?}

A empresa fez uma pesquisa para identificar a penetração dos seus produtos no mercado brasileiro. A empresa sempre considerou que parte dos seus produtos eram focados para a classe $C$ e se surpreendeu com o resultado da pesquisa. Segundo depoimento dos consumidores da classe $\mathrm{C}$, os produtos da empresa são associados a produtos caros e com o preço elevado para os padrões da classe C.

Atualmente tantos as lojas próprias como as lojas franqueadas da empresa estão concentradas nas maiores cidades. $\mathrm{Na}$ busca de encontrar novos potenciais de crescimento, a empresa fez um mapeamento detalhado de shopping centers, corredores comerciais e bairros residenciais de 135 cidades. A conclusão do mapeamento mostrou que a empresa está utilizando apena metade do seu potencial, tendo espaço para dobrar o número de loja no país. Desta maneira, o foco de crescimento se voltou para cidades médias e grandes, tanto nos shopping centers, quanto em lojas de rua. Assim, aumentou a capilaridade e a distribuição, buscando sempre atingir maior gama de classes sociais.

A empresa apresentava elevado potencial de crescimento, visto que a penetração na base de usuários potenciais era baixa. Mesmo na cidade de São Paulo, onde a presença da empresa é maior, as pesquisas indicavam que a penetração da marca não passava de $22 \%$ na classe A, 24\% na classe B1, 16\% na classe B2 e apenas 4\% na classe C. O maior limitante ao aumento de penetração da marca, principalmente nas classes B e C, era o fato da marca ser associada por esses consumidores a produtos de preços mais elevados. Com o objetivo de conquistar estes usuários, a empresa pretendia reposicionar a marca da empresa como "moda acessível", aumentando a oferta de produtos e intensificando os investimentos em propaganda. Em janeiro de 2007 a empresa lançou a primeira coleção nos moldes da nova estratégia (reposicionar a marca como moda acessivel);

- Para posicionar um produto é preciso investir em comunicação de marketing, agregando valor ao produto. Mas para reposicionar uma marca, é muito mais complexa, pois envolve mudanças na referencial internalizado do público-alvo e do seu imaginário. A empresa teria potencial para esta revolução na marca? Reflete Eduardo. 
Um longo estudo foi elaborado sobre os preços dos produtos da empresa e, em alguns casos, os preços foram reduzidos. Os produtos, como camisetas masculinas, tiveram seus preços reduzidos em 16,3\% e as calças femininas, em 21,8\%.

No entendimento da empresa, entretanto, não significava ser uma estratégia de baixar preços, e sim uma alternativa para fomentar o varejo, já a partir da próxima coleção haverá mudanças na política de preço, devido a sua estratégia de valor mais adequado aos produtos

Esta pode ser uma boa estratégia, pois para Eduardo:

- As lojas deverão ter seu preço médio de venda aumentado, pois os clientes compram produtos de moda que possuem maior valor agregado.

A indústria foco deste caso de ensino, adota um modelo de negócio caracterizado pela: produção; gestão de marcas e produtos; e varejo. Adotando um modelo de produção diferenciado, proporciona optar entre produzir seus produtos de vestuário internamente, terceirização parcial do processo produtivo, ou ainda comprar de terceiros produtos acabados tanto no mercado interno como no externo. A opção entre produzir ou terceirizar é feita com o objetivo de maximizar qualidade, custos e eficiência para atender a demanda do mercado.

A empresa apresenta um portfólio de marcas fortes (marcas "P", "X", "Y" e " $Z$ ") que apresentam posicionamentos distintos, atendendo classes sociais, e públicos diversos. Suas marcas apresentam o diferencial e os atributos reforçados pela apresentação de 6 coleções anuais, entregues em ciclos a cada duas ou três semanas, garantindo que nas lojas sempre tenha novidades, estimulando a frequência de visitas dos consumidos as lojas.

A empresa possui sob seu portfólio quatro marcas que atuam em segmentos de mercados distintos. Os produtos comercializados, para todas as marcas, incluem toda a linha de vestuário e acessórios de moda e básicos para os públicos feminino, masculino e infantil.

Para permitir a consolidação dos investimentos planejados para os próximos anos, como abertura de lojas próprias, tecnologia de informação e tecnologia industrial, a empresa precisa de uma estrutura de capital mais solida, aliada ao fortalecimento da estrutura organizacional. Para tanto a empresa precisa realizar emissões de ações na BM\&FBovespa e, como consequência, ampliar sua base de acionistas, com maior free flow.

A entrada de capital é
fundamental para proporcionar as
estratégias propostas pela empresa,
sem ela seria inviável a realização das
mesmas. Com o capital atual a empresa
não conseguiria alcançar o objetivo
proposto de dobrar o faturamento no
quadrimestre.

A empresa deve ingressar no Novo Mercado, em um segmento de listagem da BM\&FBovespa destinado à negociação de ações de empresas que adotam práticas de governança corporativa e de divulgação de informações adicionais que é exigido pela legislação.

O modelo hibrido de produção foi adotado pela empresa, que combina a produção própria, terceirizada e outsourcing (compra de produto acabado), o que proporciona flexibilidade e velocidade para atender à demanda do mercado. Este modelo leva a busca da melhor opção entre produzir internamente, terceirizar etapas do processo produtivo ou comprar o produto acabado, resultando a redução de custos com ganhos de escala e garante mais agilidade aos processos produtivos.

Ainda na década de 90 o modelo de negócio passou por um processo de desverticalização, por meio da flexibilização de processos operacionais e a intensificação da terceirização de algumas atividades (política de make or buy), o que levou a empresa a focar na expansão, qualificação e desenvolvimento da rede de fornecedores.

Os fios, produtos químicos, insumos, tecidos e produtos acabados, presentes no processo produtivos, são comprados de uma rede de aproximadamente 4.000 fornecedores do Brasil e do exterior que oferecem produtos e serviços de alta padrão de qualidade. Dentre os fornecedores internacionais, os principais estão localizados em países como China, Índia, Bangladesh, Indonésia, Tailândia, Vietnã, Uruguai, Peru e Taiwan. A empresa estabelece com seus fornecedores uma relação pautada na transparência, respeito aos contratos e preocupação com o desenvolvimento técnico e equilíbrio financeiro, adotando como prática a preferência por empresas cidadãs, possuidoras de 
alto padrão ético, boa reputação e adeptas às práticas de responsabilidade social. Para regular suas relações com fornecedores e parceiros, a empresa estabelece como práticas:

a) priorizar a seleção de parceiros e fornecedores que ofereçam alto padrão de qualidade em seus produtos e serviços, além de orçamentos e prazos condizentes com os critérios oferecidos pelo mercado;

b) aplicar, sem exceção, todos os critérios e exigências relativas ao cumprimento da legislação trabalhista, previdenciária e fiscal;

c) avaliar o impacto que os produtos ou serviços oferecidos por seus fornecedores e parceiros causam no meio ambiente, verificando as ações desenvolvidas a fim de minimizar estes impactos.

Sabendo da importância da sustentabilidade a empresa busca o desenvolvimento respeitando o meio ambiente. A água utilizada só é devolvida ao ecossistema após um tratamento biológico e físicoquímico, assim sem causar impactos ambientais. Para reduzir a emissão de poluentes na fonte, as caldeiras estão adaptadas para queima de gás natural.

Os vínculos da indústria com o meio ambiente remontam aos primeiros anos de funcionamento da unidade fabril. Os fundadores adquiriram uma extensa área desmatada nas proximidades da fábrica e realizaram o reflorestamento. Esta iniciativa conferiu em 1906, o título de Pioneiro no Reflorestamento no Brasil.

Atualmente, a empresa mantém 8,5 milhões de $\mathrm{m}^{2}$ de áreas verdes conservadas, sendo $750 \mathrm{mil} \mathrm{m}^{2}$ de reserva legal. As estratégias relacionadas ao meio ambiente estão focadas na redução do impacto ambiental e melhoria da eficiência operacional nas fábricas e lojas. A Política de Gestão Ambiental visa atender à legislação, adotando práticas que minimizem os impactos ambientais da operação. As principais ações são:

- Comissão Interna de Conservação de Energia (CICE): que tem por objetivo controlar consumo de água, energia, combustíveis, gerando indicadores e estabelecendo metas para a melhoria contínua e mitigação de impactos. A organização prioriza energias limpas, sendo o maior consumo de energia elétrica proveniente de PCH's, (pequenas centrais hidrelétricas) e matriz de combustível baseada no uso de lenha de reflorestamento e gás natural;

- Programa de Gestão de Resíduos Sólidos (PGRS): cujo objetivo é a gestão dos resíduos produzidos nas plantas industriais, bem como ações de controle e regulamentação necessários. As unidades com maior geração de resíduos sólidos possuem programa consistente de gerenciamento de resíduo, com controle do descarte e reciclagem realizado por empresas qualificadas e licenciadas;

- Certificação FSC (Forest Stewardship Council) nas embalagens de produtos (sacolas, cartuchos e caixas).

Para aumentar a oferta de crédito na rede Store será ofertado aos clientes um cartão do tipo private label, com características comparáveis às de outros cartões no mercado. A estratégia será complementada por um cartão co-branded e produtos adicionais, como crédito pessoal e seguro. A empresa planejou expandir a operação do cartão com base em um acordo comercial com uma instituição financeira, baseado em compartilhamento de resultados e de riscos. Como resultado da implantação, a empresa ganha no aumento das vendas e do ticket médio (valor médio de compras por cliente).

A empresa objetivou aumentar o número de lojas próprias, dentro da rede Store, normalmente lojasmodelo de maior tamanho, em torno de $200 \mathrm{~m}^{2}$ a $240 \mathrm{~m}^{2}$. Nas maiores cidades, nas quais a presença da empresa ainda é discreta, é que existe prioridade na abertura, por exemplo, a cidade do Rio de Janeiro, ou shopping centers de alto fluxo, voltados para as Classes A e B. O objetivo de tal estratégia é controlar os pontos de alta visibilidade e fortalecer a construção da marca.

A tecnologia de última geração está presente nas operações fabris da empresa, possibilitando agilidade na entrega de elevados volumes de produtos, com alto padrão de qualidade. A tecnologia proporciona eficiência na produção, minimiza desperdícios de matériaprima, emelhorcontroledos custos. Paramanter esta tecnologia, são realizados investimentos tanto no parque fabril com a aquisição de equipamentos e modernização da estrutura, bem como no treinamento e desenvolvimento dos colaboradores, com foco no relacionamento interpessoal e desenvolvimento do clima organizacional. 
Nas operações com os terceiros e na compra de produtos acabados (outsourcing) a Companhia busca fornecedores que produzam artigos com valor agregado e tecnologias avançadas. Para garantir o padrão destes produtos, a empresa possui uma equipe de Controle de Qualidade que dá suporte aos fornecedores e inspeciona todos os itens recebidos.

A empresa possui dois centros de distribuição, estrategicamente localizados, em Blumenau, estado de Santa Catarina, e em Anápolis, estado de Goiás. A partir deles, é possível atender a todas as lojas das redes Store, bem como todos os clientes do Varejo Multimarcas. Os centros de distribuição recebem os produtos acabados das unidades de produção e de terceiros contratados (outsourcing) já devidamente embalados e etiquetados com códigos de barras. Ao serem entregues ao transporte rodoviário, os produtos são separados de acordo com o roteiro previamente planejado, maximizando a eficiência logística e reduzindo ao máximo o tempo de entrega e custo do transporte. Como estes serviços são totalmente terceirizados, é feito um contínuo monitoramento, além de ser adotada uma política de remuneração com base na eficiência dos resultados para incentivar a prestação de serviço rápido e preciso.

Os sistemas de logística são integrados aos canais de distribuição e vendas, de um lado, e aos sistemas de produção e compra de terceiros, de outro. Com essa integração, é possível controlar e determinar a quantidade e a periodicidade das distribuições, de acordo com a demanda no ponto de venda, os níveis de estoque, as características dos produtos e a localização dos pontos de vendas.

\section{Chegou o momento de tomar uma decisão}

A estratégia de negócio da empresa tem como objetivo o desenvolvimento de suas quatro marcas (marcas "P", "X", "Y" e "Z"), através de planos de crescimento dentro do perfil de cada uma e focados no posicionamento, gestão de marca, distribuição e comunicação de marketing.

Para a marca principal da empresa (marca "P"), maior ativo da indústria, o plano estratégico iniciado em 2007, com o lançamento da coleção de Alto Verão vêm demonstrando resultados expressivos. Este plano contempla i) o reposicionamento dos preços; ii) ajustes nas coleções para melhor atender ao público alvo; iii) expansão da rede de lojas Store dentro de um modelo arquitetônico diferenciado e iv) aumento no número de clientes multimarcas. Aliado a isso, as campanhas de marketing, o cartão de crédito e a loja virtual da marca também são responsáveis pelo crescimento da marca.

Eduardo está com dúvidas se as estratégias apresentadas são as mais adequadas para o cenário em que a empresa vive atualmente. Muitas dúvidas surgem na mente do acionista. Seriam estas as melhores estratégias para a empresa? Seria o momento mais adequado para executar determinadas estratégias? Não existiriam estratégias mais adequadas?

Estas duvidas remete Eduardo a nossa questão central, como fazer a empresa dobrar o faturamento?

\section{Anexo}

Quadro 2 . Portfolio das marcas e seus públicos.

\begin{tabular}{|c|c|c|}
\hline Marca & Público & Classe \\
\hline Principal & Adultos & Todas as classes sociais \\
\hline X & Infantil & Todas as classes sociais \\
\hline Y & Infantil & Classe A e B \\
\hline Z & Infantil & Classe A e B \\
\hline
\end{tabular}

Fonte: Site da empresa

Quadro 3 . Unidades produtivas

\begin{tabular}{|c|c|}
\hline Estado & Quantidade de unidades \\
\hline Santa Catarina & 5 unidades produtivas \\
\hline Goiás & 4 unidades produtivas \\
\hline Rio Grande do Norte & 1 unidades produtivas \\
\hline
\end{tabular}

Fonte: Site da empresa

\section{Quadro 4 . Insumo importado}

\begin{tabular}{|c|c|}
\hline Insumo & \% insumo importado \\
\hline Fiação & $65 \%$ insumo importado \\
\hline Área química & $15 \%$ insumo importado \\
\hline $\begin{array}{c}\text { Produto acabado } \\
\text { (outsourcing) }\end{array}$ & $80 \%$ é feito no exterior \\
\hline
\end{tabular}

Fonte: Site da empresa 
Quadro 5 . Penetração de mercado por classe social

\begin{tabular}{|c|c|}
\hline Classe & \% de penetração \\
\hline Classe A & $22 \%$ \\
\hline Classe B1 & $24 \%$ \\
\hline Classe B2 & $16 \%$ \\
\hline Classe C & $4 \%$ \\
\hline
\end{tabular}

Fonte: Site da empresa

Quadro 6. Oferta pública de ações

\begin{tabular}{|c|c|c|}
\hline Investidores & $\mathbf{\%}$ & Valor em milhões \\
\hline Estrangeiros & 63,11 & 196,7 \\
\hline Nacionais & 25,44 & 79,3 \\
\hline Pessoas Físicas & 11,45 & 35,7 \\
\hline Total & & $\mathbf{3 1 1 , 6}$ \\
\hline
\end{tabular}

Fonte: Site da empresa

\section{Notas de ensino}

\section{Fonte de Dados}

As informações descritas neste caso de ensino foram obtidas por meio da observação participante, visita ao museu da empresa, consulta a sites da empresa de relações com investidores; site da BM\&FBovespa além do próprio site da empresa e entrevistas com funcionários de diversos níveis hierárquicos da empresa.

\section{Objetivos Educacionais}

O caso tem por objetivo levar os alunos a vivenciar decisões relacionadas ao processo de tomada de decisão das estratégias organizacionais, discutindo as estratégias adotada pela empresa com base no método clássico de formulação da estratégia descrito por Porter. A proposta é fazer com que os estudantes se coloquem no lugar dos acionistas da empresa, para analisar as estratégias tomadas pela empresa, analisando cada estratégia dentro da roda de estratégia competitiva de Porter (2004).

O caso deve desenvolver nos alunos, (i) familiaridade com o ambiente estratégica de uma organização, e seu processo de formulação das estratégias. (ii) senso crítico sobre formulação das estratégias, tipos de estratégias organizacionais, e o processo de decisão, avaliando seus pontos fortes e fracos de cada escolha estratégica. (iii) proporcionar conhecimento sobre o processo de reposicionamento da marca.

\section{Utilização Recomendada}

O caso foi desenvolvido para ser usado em programas de pós-graduação para discussão do processo de formulação das estratégias organizacionais e processo de reposicionamento da marca. Se adaptarmos as perguntas pode ser usado para alunos da graduação nas disciplinas de modelos de gestão.

O professor pode pedir para a sala se dividir em grupos de no máximo 4 alunos, para lerem e discutirem o caso. Disponibilizar tempo de 30 minutos para esta etapa.

$\mathrm{Na}$ etapa sequente, após a leitura pelos grupos, o professor pode abrir a discussão para o grande grupo, deixar 30 minutos para os alunos debaterem as respostas das questões de discussão.

Nos últimos 30 minutos o professor deve usar para fazer um fechamento, fazendo suas observações do que foi discutido pelos alunos e apresentar os dados do caso apresentado nas notas de ensino. Informando que a empresa conseguiu alcançar seus objetivos com as estratégias propostas. E também apresentar as estratégias empregadas pela empresa após a obtenção do objetivo de dobrar a faturamento no quadriênio (2007-2010). O professor pode apresentar estas novas estratégias (20112017) como opções de estratégias que poderiam ser usadas também para dobrar o faturamento.

Estratégias empregadas pela empresa após a obtenção do objetivo de dobrar a faturamento: De 2010 até os dias atuais a empresa manteve sua estratégia de explorar o alto potencial apresentado pela marca, com foco em ações tanto nas vendas para a rede Store quanto para o canal varejo multimarca. $\mathrm{Na}$ rede de lojas, o crescimento se deu pela expansão da rede Store e pelo crescimento das vendas no conceito mesmas lojas. Em 2012 a empresa fez um estudo de potencial de expansão da rede de lojas, onde foi indicado que as lojas Store tem um potencial de alcançar 796 lojas. Este estudo levou em consideração, as atuais premissas socioeconômicas de consumo, distribuição de renda e de penetração da marca, e introduzindo maior foco na abertura de lojas em cidades pequenas e médias.

No mercado infantil, a empresa introduziu uma nova estratégia de negócios para as suas duas linhas infantil. 
Ajustes foram feitos no posicionamento das marcas infantil da empresa, como mudanças no sortimento de produtos e faixas de preços, de forma a focar a marca "X" nos segmentos "Value" e "Moderate" em um conceito definido como a versão mini-adulto da marca principal - e a marca "Y" nos segmentos "Better" e "Premium".

Com este novo estratégia a empresa iniciou o processo que levaria a abertura de quatro lojas pilotos das marcas infantis. Ao final de 2011, com cinco lojas da marca infantil " $X$ " cujos resultados se mostraram bastante positivos, foram feitos estudos iniciais que indicaram potencial para uma rede neste formato com 200 a 250 lojas, com tamanho de aproximadamente $60 \mathrm{~m} 2$. Durante o ano de 2012, foram inauguradas 22 lojas da marca infantil " $\mathrm{X}$ ”, sendo uma loja própria e vinte e uma franquias.

Após implementação de uma estrutura especifica de logística e distribuição para atender ao canal varejo online de forma mais eficiente no final de 2011, e investimentos em TI, foi inaugurada em 2012 uma nova webstore, proporcionando uma experiência de compra mais agradável ao consumidor, de modo a impulsionar o contínuo crescimento das vendas online.

Para as duas marcas infantis da Empresa, o plano de crescimento, iniciado em 2010 contempla o posicionamento das marcas em linha com o mercado alvo de cada uma, ajustes no sortimento dos produtos e faixas de preços e investimentos em campanhas de marketing voltadas ao público infantil. Foram lançadas até o final de 2012 vinte e sete lojas da marca infantil "X", com formato de loja exclusiva e com um corner para a marca infantil " $Y$ '.

A marca de produtos para jovens também foi alvo de um plano de reposicionamento para alinhar os produtos ao conceito jeans casual da marca. Este plano foi iniciado em 2009 e também focou na qualificação da rede de distribuição e campanhas de marketing voltadas ao público jovem, antenado em moda. Em 2010 foi inaugurada uma loja piloto exclusiva para a marca de produtos jovens que nos anos seguinte viriam a abrir novas lojas com intuito de desenvolver a marca.
Em 31 de dezembro de 2012 a estrutura de varejo da empresa era composta por uma rede de 621 lojas em todos os Estados Brasileiros e 17 lojas franqueadas no exterior, mais de 17.000 clientes no varejo multimarcas e as lojas virtuais.

Seguindo a escala de dificuldade apresentada por Leenders e Erskine (1989), este caso de ensino apresenta os 3 níveis de dificuldade, conforme quadro 7, onde 1 é considerado um nível fácil, 2 é nível regular, e 3 nível difícil. 
Quadro 7 . Nível de dificuldade do caso de ensino

\begin{tabular}{|c|c|c|c|c|}
\hline Dimensão & Nível & Informação & Nível de dificuldade & Propósito \\
\hline Analítica & 3 & $\begin{array}{c}\text { O caso } \\
\text { apresenta a } \\
\text { situação e } \\
\text { o contexto } \\
\text { ambiental da } \\
\text { decisão. }\end{array}$ & $\begin{array}{c}\text { O desfecho do caso não é } \\
\text { apresentado. O importante } \\
\text { para o aluno não é qual escolha } \\
\text { foi feita e se foi acertada, } \\
\text { mas sim discutir as opções } \\
\text { existentes e quais suas possíveis } \\
\text { consequências. }\end{array}$ & $\begin{array}{c}\text { Apresenta o propósito de desenvolver } \\
\text { no aluno a habilidade de análise do } \\
\text { cenário na empresa, e do mercado, } \\
\text { estudando as opções disponíveis } \\
\text { diante da situação em que a empresa } \\
\text { se encontra e tomar as decisões } \\
\text { aceitando as consequências geradas } \\
\text { pela tomada de decisão. }\end{array}$ \\
\hline Conceitual & 2 & $\begin{array}{c}\text { O uso de vários } \\
\text { conceitos } \\
\text { importantes } \\
\text { para estratégia, } \\
\text { com nível } \\
\text { médio de } \\
\text { dificuldade. }\end{array}$ & $\begin{array}{c}\text { É necessária uma aula } \\
\text { expositiva sobre o tema, ou } \\
\text { pelo menos uma leitura prévia } \\
\text { extraclasse, para se ter uma } \\
\text { visão geral dos principais } \\
\text { conceitos e termos estratégicos } \\
\text { usados no caso. }\end{array}$ & $\begin{array}{c}\text { Propósito de conhecimento } \\
\text { teórico e prático sobre estratégias } \\
\text { organizacionais. }\end{array}$ \\
\hline Apresentação \\
$\begin{array}{c}\text { Dadose } \\
\text { informações } \\
\text { apresentadas de } \\
\text { forma clara. }\end{array}$ & $\begin{array}{c}\text { A leitura do caso é rápida, } \\
\text { proporcionando a leitura em } \\
\text { sala, sem a necessidade de } \\
\text { leitura prévia do caso de ensino. } \\
\text { Os dados fornecidos no caso } \\
\text { são suficientes para se analisar } \\
\text { o caso. }\end{array}$ & $\begin{array}{c}\text { Informações relevantes para a análise, } \\
\text { desconsiderou-se dados irrelevantes } \\
\text { para caso. }\end{array}$ \\
\hline
\end{tabular}

Fonte: Adaptado de Leenders e Erskine (1989, p. 120).

\section{Proposta de Plano de Ensino}

O ideal é que o professor já tenha feito uma aula expositiva sobre os principais conceitos discutidos no caso. Se isso não for possível, deveria reservar uns 30 minutos do início da aula para apresentar estes conceitos aos alunos.

De forma a melhor aproveitar o caso, sugere-se um tempo de aproximadamente 1 h e $50 \mathrm{~min}$, de forma a permitir: breve exposição dos conceitos, organização dos grupos, discussão do caso entre os alunos do seu grupos, discussão do caso no grande grupo, com a moderação do professor, considerações do professor com relação as das análises feitas pelo grupos, apontando os principais pontos levantados no debate e por fim o fechamento do professor mostrando que não existe uma única resposta ou uma resposta mais assertiva ao caso estudado.

Quadro 8 . Plano de ensino

\begin{tabular}{|c|c|}
\hline Atividade & $\begin{array}{c}\text { Duração } \\
\text { (minutos) }\end{array}$ \\
\hline Breve exposição dos conceitos trabalhados na aula anterior & 10 \\
\hline Organizar grupos de quatro alunos & 02 \\
\hline Distribuição do caso e leitura pelos alunos & 14 \\
\hline Discussão do caso entre os membros de cada grupo & 14 \\
\hline Discussão do caso no grande grupo, com moderação do professor & 30 \\
\hline Considerações das análises feitas pelo grande grupo, apontando os principais pontos levantados no debate & 20 \\
\hline $\begin{array}{c}\text { Fechamento do professor mostrando que não existe uma única resposta ou uma resposta mais assertiva } \\
\text { ao caso estudado }\end{array}$ & 10 \\
\hline
\end{tabular}

Fonte: Elaborado pelos autores 


\section{Questões para discussão do caso em sala de aula}

1. Identifique no caso, dentre as 10 políticas operacionais citada na roda da estratégia competitiva de Porter, quais são apresentadas no caso?

2. A Análise SWOT, é uma ferramenta de planejamento muito utilizada para monitorar tanto o ambiente interno como o ambiente externo da organização, ajudando no processo de tomada decisão organizacional. Elaborar uma Análise SWOT, identificando exemplos de pontos fortes, pontos fracos, ameaças e oportunidades da empresa.

3. Entre os tipos de reposicionamento, (reposicionamento reativo; propositivo; corretivo e adaptativo), qual dos reposicionamentos a empresa adotou? Argumente sua resposta, com aspectos que justificam o uso do tipo de reposicionamento.

4. A indústria, foco deste caso de ensino, adota um modelo de negócio caracterizado pela: produção; gestão de marcas e produtos; e varejo. Qual o diferencial presente no caso com relação a produção, marcas e varejo?

5. A Gestão da Sustentabilidade se tornou importante no processo decisório das organizações, a medida que a sociedade vem se tomando mais consciente e mostrando ser um importante influenciador nas ações que as organizações desenvolvem com relação ao meio ambiente. Quais ações são desenvolvidas pela organização com relação a sustentabilidade organizacional?

\section{Análise do caso e dinâmica de discussão em plenário}

1. Identifique no caso, dentre as 10 políticas operacionais citada na roda da estratégia competitiva de Porter, quais são apresentadas no caso?

Para se manter no mercado, as empresas precisam ter estratégias competitivas. Para Porter (2004), a estratégia competitiva é o desenvolvimento de um formula macro, de acordo com o modelo em que a empresa adotar competir. Quais as metas e suas respectivos políticas para realizar as metas com eficácia.

O método clássico para formulação de estratégias, é apresentado por Porter (2004) através da roda da estratégia competitiva. No centro da roda encontrase as metas da empresa, também conhecido como, missão, objetivo, que são as diretrizes gerais da empresa informando a forma como a empresa pretende competir no mercado para alcançar tanto objetivos econômicos, como não econômicos. Os raios são as políticas operacionais, com a qual a empresa almeja realizar suas metas, as políticas devem originar das metas, que são as diretrizes norteadoras da empresa.

Figura 1. A roda da estratégia Competitiva

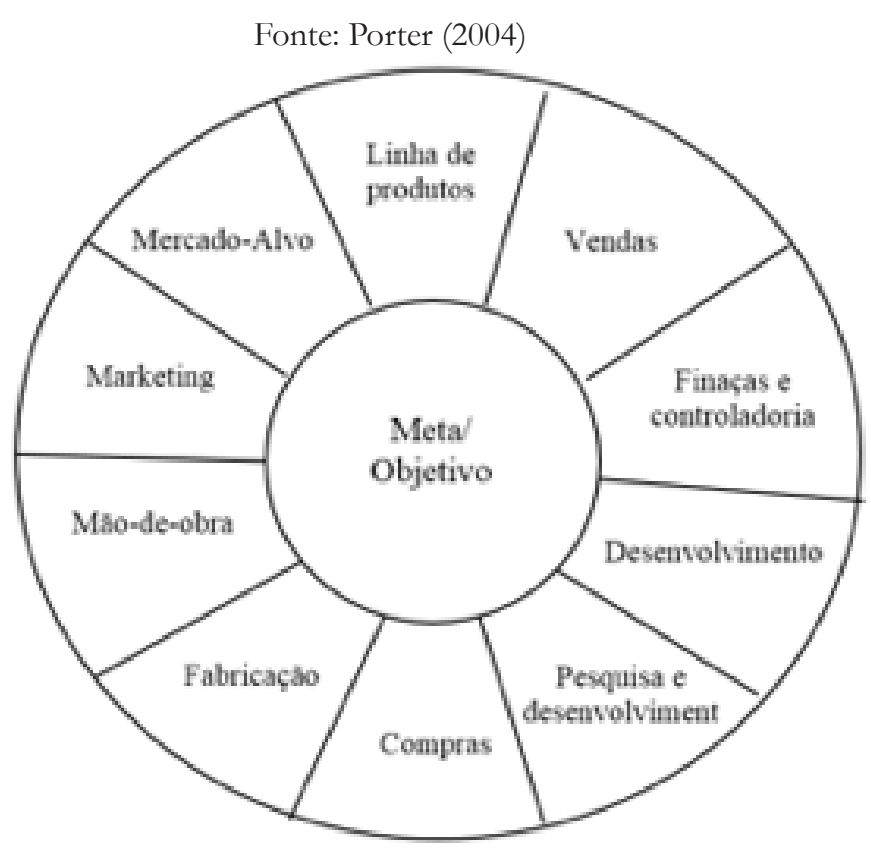


Quadro 9. Roda da estratégia

\begin{tabular}{|c|c|c|}
\hline Política & Estratégia da empresa do caso de ensino & Referências \\
\hline Mercado-Alvo & $\begin{array}{l}\text { Reposicionar a marca como moda acessível: A empresa apresentava elevado } \\
\text { potencial de crescimento, visto que a penetração na base de usuários potenciais } \\
\text { era baixa. Mesmo na cidade de São Paulo, onde a presença da empresa é maior, } \\
\text { as pesquisas indicavam que a penetração da marca não passava de } 22 \% \text { na } \\
\text { classe A, } 24 \% \text { na classe B1, } 16 \% \text { na classe B2 e apenas } 4 \% \text { na classe C. O maior } \\
\text { limitante ao aumento de penetração da marca, principalmente nas classes B e C, } \\
\text { era o fato da marca ser associada por esses consumidores a produtos de preços } \\
\text { mais elevados. Com o objetivo de conquistar estes usuários, a empresa pretendia } \\
\text { reposicionar a marca da empresa como "moda acessível", aumentando a oferta } \\
\text { de produtos e intensificando os investimentos em propaganda. Em janeiro } \\
\text { de } 2007 \text { a empresa lançou a primeira coleção nos moldes da nova estratégia } \\
\text { (reposicionar a marca como moda acessível); }\end{array}$ & $\begin{array}{c}\text { Furrier } \\
(2008) \\
\text { Telles (2004) }\end{array}$ \\
\hline Marketing & $\begin{array}{l}\text { Buscar relação de valor mais adequada para os produtos da empresa: a empresa } \\
\text { elaborou um longo estudo sobre os preços dos produtos e, em alguns casos, os } \\
\text { preços foram reduzidos. Os produtos, como camisetas masculinas, tiveram seus } \\
\text { preços reduzidos em } 16,3 \% \text { e as calças femininas, em } 21,8 \% \text {. No entendimento } \\
\text { da empresa, a estratégia adotada pela empresa, não significava uma estratégia de } \\
\text { baixar preços, e sim uma alternativa para fomentar o varejo. Em algumas lojas, o } \\
\text { preço médio de venda aumentou, pois, os clientes compram produtos de moda } \\
\text { que possuem maior valor agregado. Os clientes perceberam em janeiro de } 2007 \\
\text { na coleção de alto verão que a empresa havia mudado a sua política de preço, } \\
\text { devido a sua estratégia de valor mais adequado aos produtos; }\end{array}$ & $\begin{array}{l}\text { Dolan; } \\
\text { Simon } \\
(1998) \\
\text { Kotler } \\
(2001) \\
\text { Sardinha } \\
(1995)\end{array}$ \\
\hline Vendas & 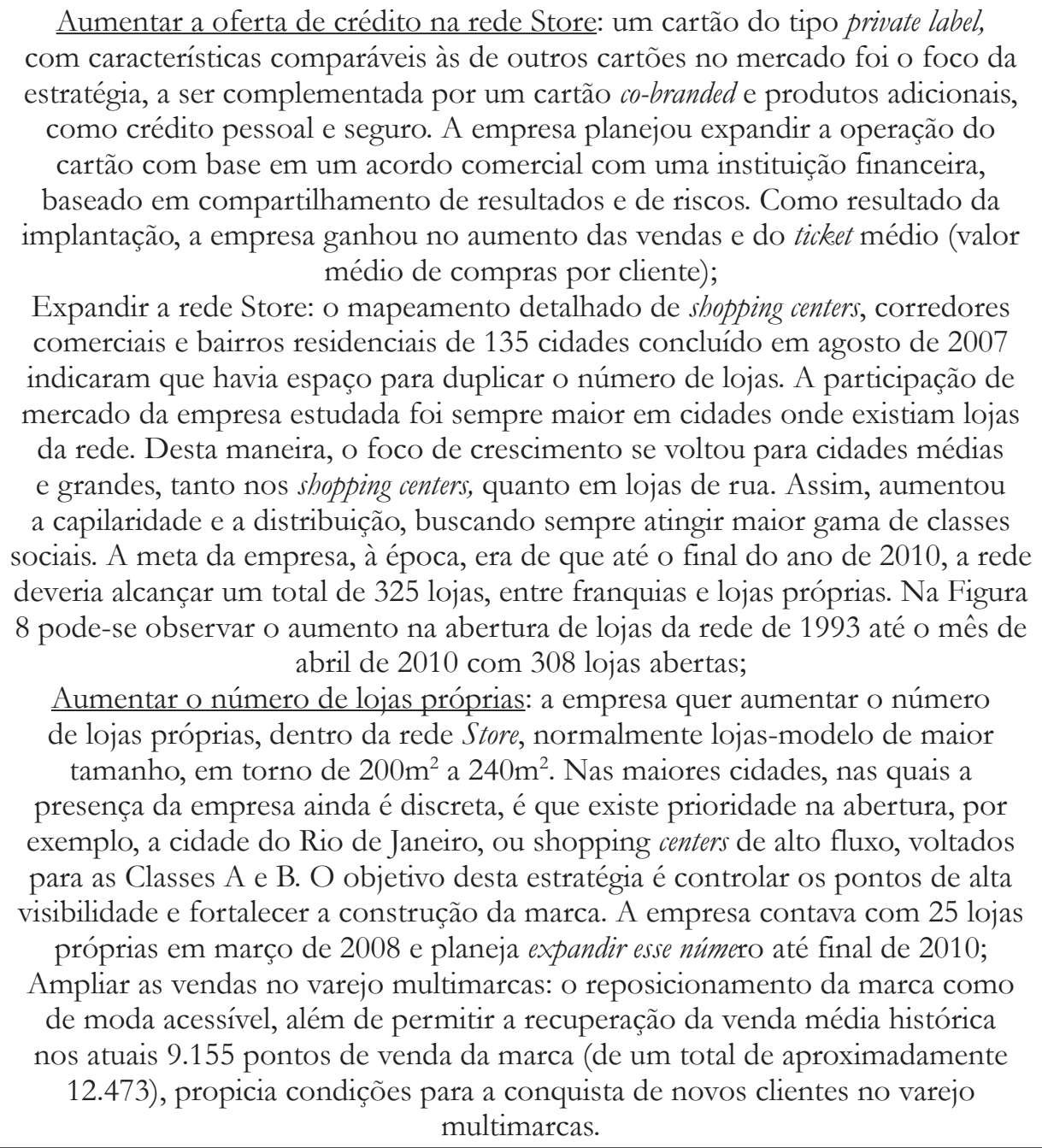 & $\begin{array}{c}\text { Park } \\
\text { (1988) } \\
\text { Alves; } \\
\text { Menezes } \\
\text { (2007) }\end{array}$ \\
\hline
\end{tabular}




\begin{tabular}{|c|c|c|}
\hline Desenvolvimento & $\begin{array}{l}\text { O portfólio de marcas da Companhia é composto por marcas fortes e } \\
\text { com posicionamentos distintos. O diferencial e os atributos das marcas são } \\
\text { reforçados pelo desenvolvimento de } 6 \text { coleções ao longo do ano, entregues em } \\
\text { ciclos a cada duas ou três semanas, o que garante que sempre haja novidades nas } \\
\text { lojas e estimula a frequência de visita dos consumidores. }\end{array}$ & $\begin{array}{l}\text { Townsend; } \\
\text { Cavusgil; } \\
\text { Baba } \\
\text { (2010) }\end{array}$ \\
\hline Fabricação & $\begin{array}{l}\text { O modelo de produção híbrido é um dos diferenciais da empresa e é } \\
\text { caracterizado pela combinação de produção própria, terceirizada e outsourcing } \\
\text { (compra de produto acabado), garantindo flexibilidade e velocidade para atender } \\
\text { à demanda do mercado. Este modelo permite buscar a melhor opção entre } \\
\text { produzir internamente, terceirizar etapas do processo produtivo ou comprar o } \\
\text { produto acabado (make or buy), o que traz redução de custos com ganho de escala } \\
\text { e garante mais agilidade aos processos produtivos. }\end{array}$ & $\begin{array}{l}\text { Rentes et al. } \\
\quad(2005) \\
\text { Wang; Xu } \\
\quad(1997)\end{array}$ \\
\hline Mão-de-obra & $\begin{array}{c}\text { São realizados investimentos tanto no parque fabril com a aquisição de } \\
\text { equipamentos e modernização da estrutura, bem como no treinamento e } \\
\text { desenvolvimento dos colaboradores, com foco no relacionamento interpessoal e } \\
\text { desenvolvimento do clima organizacional. }\end{array}$ & $\begin{array}{l}\text { Macêdo } \\
(2007) \\
\text { Marras } \\
(2009)\end{array}$ \\
\hline Compras & $\begin{array}{l}\text { Desde a década de } 90 \text {, a empresa passou por um processo de desverticalização } \\
\text { do modelo de negócio, mediante a flexibilização de processos operacionais } \\
\text { e a intensificação da terceirização de determinadas atividades (política de } \\
\text { make or buy). A adoção dessa política de flexibilidade levou a empresa a focar } \\
\text { na expansão, qualificação e desenvolvimento da rede de fornecedores. No } \\
\text { processo produtivo, os fios, produtos químicos, insumos, tecidos e produtos } \\
\text { acabados são comprados de uma rede de aproximadamente } 4.000 \text { fornecedores } \\
\text { de primeira qualidade, brasileiros e internacionais. Na fiação e na área química } \\
\text { aproximadamente } 65 \% \text { e } 15 \% \text {, respectivamente, são insumos importados. Da } \\
\text { compra de produtos acabados (outsourcing), } 80 \% \text { é feita no exterior. Dentre os } \\
\text { fornecedores internacionais, os principais estão localizados em países como } \\
\text { China, Índia, Bangladesh, Indonésia, Tailândia, Vietnam, Uruguai, Peru e } \\
\text { Taiwan. }\end{array}$ & $\begin{array}{l}\text { Rezende } \\
\text { (1997) }\end{array}$ \\
\hline $\begin{array}{c}\text { Pesquisa e } \\
\text { desenvolvimento }\end{array}$ & $\begin{array}{c}\text { A empresa fez uma pesquisa para identificar a penetração dos produtos da } \\
\text { empresa no mercado brasileiro. A empresa sempre considerou que parte dos } \\
\text { seus produtos eram focados para a classe C e se surpreendeu o resultado da } \\
\text { pesquisa. }\end{array}$ & $\begin{array}{l}\text { Dunning } \\
(2009)\end{array}$ \\
\hline $\begin{array}{c}\text { Finanças e } \\
\text { controladoria }\end{array}$ & $\begin{array}{l}\text { Aumentar a oferta pública de ações: a empresa realizou emissão de ações na } \\
\text { BM\&FBovespa e, desde então, ampliou sua base de acionistas, com maior free } \\
\text { flow. A estrutura de capital mais sólida, aliada ao fortalecimento da estrutura } \\
\text { organizacional, permitiu a consolidação dos investimentos planejados para } \\
\text { os próximos anos, em abertura de lojas próprias, tecnologia de informação } \\
\text { e tecnologia industrial. A organização em junho de } 2007 \text { ingressou no } \\
\text { Novo Mercado, em um segmento de listagem da BM\&FBovespa destinado } \\
\text { à negociação de ações de empresas que adotam práticas de governança } \\
\text { corporativa e de divulgação de informações adicionais que é exigido pela } \\
\text { legislação. A empresa encerrou sua oferta pública de ações com captação de } \\
\text { R\$311,6 milhões. Os investidores estrangeiros ficaram com } 63,11 \% \text { dos papéis } \\
\text { distribuídos, os fundos de investimento nacionais com } 25,44 \% \text { e pessoas físicas } \\
\text { com } 11,45 \% \text {; }\end{array}$ & $\begin{array}{c}\text { BM\&F } \\
\text { Bovespa } \\
(2014)\end{array}$ \\
\hline Linha de produtos & $\begin{array}{l}\text { O modelo de produção diferenciado permite optar entre produzir internamente } \\
\text { artigos de vestuário, terceirizar partes do processo produtivo, ou comprar artigos } \\
\text { acabados de terceiros (no mercado interno e externo). A opção entre produzir } \\
\text { ou terceirizar é feita com o objetivo de maximizar qualidade, custos e eficiência } \\
\text { para atender a demanda do mercado. }\end{array}$ & $\begin{array}{l}\text { Porter, } \\
(2004) \\
\text { Stuckey; } \\
\text { White (1993) } \\
\text { Wright et. al. } \\
\quad(1998)\end{array}$ \\
\hline
\end{tabular}

Ao analisar o desempenho organizacional, deve levar em consideração as decisões estratégicas tomadas pelos gerentes, afim de identificar as ações gerencias sobre o resultado da empresa. Segundo Rumelt, Schendel, Teece, (1991), a capacidade do gestor na tomada de decisão assertiva, pode ser avaliada pelo desempenho 
organizacional que reflete os direcionamentos, as escolhas, as decisões das gerencias inseridas num contexto social com muitas incertezas.

A estratégia está presente no cotidiano das organizações, nos últimos anos os pesquisadores (WHITTINGTON, 2006, ROULEAU, 2005) estão focando as questões micro organizacionais, as estratégias do dia a dia, as atividades realizadas pelos empregados, cabendo ao gerente operacional a tarefa de controlar a equipe e coordenar as pessoas para que se possa aproveitar melhor o potencial de cada empregado, para que se desenvolva ação gerando vantagem competitiva para organização.

A vantagem competitiva segundo Porter (1985), sustenta que a competitividade organizacional, é apoiada pela escolha das estratégias adotadas pela organização, a escolha inadequada pode levar ao fracasso. As empresas que obtém seu desempenho acima da média, atribuem este resultado à existência de vantagem competitiva, ou seja, a criação de valor superior aos dos concorrentes, (PETERAF e BARNEY, 2003). Para Powell, (2001), a vantagem competitiva é apontada como peça chave que pode explicar o excelente desempenho das organizações, tornando o principal foco, da gestão estratégica. Tanto nos estudos da estratégia, como nos relacionado a tomada de decisão, está presente estudos da vantagem competitiva.

A vantagem competitiva se comporta como o esteio organizacional em muitos estudos sobre estratégia, servindo para explicar o desempenho superior das empresas (POWELL, 2001). Para Porter, (1985) vantagem competitiva surge, fundamentalmente, do valor que uma empresa é capaz de criar para seus compradores, valor este que excede o custo da empresa em criá-lo.

Buscando conceitos no passado identificamos Ansoff (1965, p.93) onde vantagem competitiva procura identificar propriedades específicas e combinações individuais de produtos e mercados que dão à empresa uma forte posição concorrencial. Conceitos mais recentes como de Peteraf e Barney, (2003, p. 314), uma empresa tem vantagem competitiva se for capaz de criar mais valor econômico do que o concorrente em seu mercado de produto. Os conceitos não estão consolidados, mostrando que o tema não está esgotado, onde estudos relacionados a vantagens competitivas são bem-vindos e necessários.
Considerando os processos de mudanças vivenciados continuamente pelas organizações, a agilidade passa a ser um ponto estratégico, sendo que não há mais tempo para se sucumbir a lentidão das organizações burocráticas, é preciso velocidade para obter vantagens competitivas. Esta agilidade requer a participação dos diferentes níveis organizacionais no processo de tomada de decisão, que não pode esperar que a informação "suba" para os níveis tradicionalmente responsáveis pelo processo decisório, requerendo muitas vezes, que a decisão seja emergente, na hora da realização da prática ou de determinada atividade do dia a dia da organização.

2. A Análise SWOT, é uma ferramenta de planejamento muito utilizada para monitorar tanto o ambiente interno como o ambiente externo da organização, ajudando no processo de tomada decisão organizacional. Elaborar uma Análise SWOT, identificando exemplos de pontos fortes, pontos fracos, ameaças e oportunidades da empresa.

A análise é SWOT, segundo Kotler, Keller, (2006), é uma ferramenta de planejamento muito utilizada para monitorar tanto o ambiente interno como o ambiente externo da organização, ajudando no processo de tomada decisão organizacional. A ferramenta ajuda na análise do ambiente interno, identificando os pontos fortes e fracos da empresa, bem como no ambiente externa, identificando as oportunidades e ameaças da empresa.

\begin{tabular}{|c|c|}
\hline $\begin{array}{c}\text { Pontos Fortes } \\
\text { - Centro de distribuição } \\
\text { bem localizadas } \\
\text { - Estar em diversos canais } \\
\text { de distribuição: varejo, } \\
\text { franquia, web e loja } \\
\text { própria } \\
\text {-Marca reconhecida pela } \\
\text { qualidade } \\
\text { - }\end{array}$ & $\begin{array}{c}\text { Oportunidade } \\
\text { - Potencial de crescimento } \\
\text { no mercado interno } \\
\text { - Expansão das exportações }\end{array}$ \\
\hline $\begin{array}{l}\text { Pontos Fracos } \\
\text { - Não usar todo o } \\
\text { potencial de vendas, } \\
\text { deixando de estar } \\
\text { presente em cidades } \\
\text { grandes }\end{array}$ & $\begin{array}{c}\text { Ameaça } \\
\text { - Dependência de algumas } \\
\text { matérias primas importadas, } \\
\text { o que pode ser um risco } \\
\text { devido a variação do } \\
\text { câmbio em um senário } \\
\text { política e econômico } \\
\text { turbulento. } \\
\text { - Política/ Economia }\end{array}$ \\
\hline
\end{tabular}


3. Entre os tipos de reposicionamento, (reposicionamento reativo; propositivo; corretivo e adaptativo), qual dos reposicionamentos a empresa adotou? Argumente sua resposta, com aspectos que justificam o uso do tipo de reposicionamento.

O reposicionamento segundo Cobra (2008), pode ser aplicado em qualquer segmento, $\mathrm{O}$ reposicionamento apresenta 4 tipologias conforme Furrier (2008); Telles (2004): reposicionamento reativo; reposicionamento propositivo; reposicionamento corretivo e reposicionamento adaptativo.

- Reativo: tem como foco recuperar os valores perdidos da marca, causados pelas mudanças ambientais ligada a questões como cultura, economia, política ou tecnologia. Está mudanças enfraquecem as marcas conduzindo ao reajuste do novo ambienta.

- Propositivo: Proporciona o melhor desempenho organizacional ou melhor aproveitar a oportunidade do mercado, onde para aproveitar esta oportunidade é preciso mudar o posicionamento atual da empresa.

- Corretivo: É adotado quando o posicionamento atual não é ineficiente, não atendendo mais aos objetivos atuais da marca. O posicionamento atual não agrega valor ao seu público-alvo.

- Adaptativo: Adotado quando busca proporcionar maior eficiência a comunicação organizacional em relação ao seu público-alvo

A empresa reposicionou sua marca através da tipologia reativa, entre os anos de 2000 a 2006 a empresa aposta na valorização das marcas, reduzindo o número das marcas comercializadas, concentrando-se apenas nas marcas próprias. A empresa tinha a licença de marcas conhecidas nacional e internacionalmente e optou estrategicamente em descontinuar, visto que, mesmo com uma venda muito boa dos produtos, proporcionava uma margem de lucro muito baixa, exigindo um capital de giro muito alto. Com esta estratégia a empresa trocou crescimento por sustentabilidade, o que estava de acordo aquele momento que a empresa estava passando. A Empresa retoma a estratégia de crescimento, contratando uma empresa de consultoria especializada em planejamento estratégico.

Entre as suas principais diretrizes estratégicas entre os anos de 2007 até 2010, a empresa adotou o reposicionamento da marca principal da empresa, como moda acessível, para tanto, ela adotou o reposicionamento corretivo.

A empresa apresentava elevado potencial de crescimento, visto que a penetração na base de usuários potenciais era baixa. Mesmo na cidade de São Paulo, onde a presença da empresa é maior, as pesquisas indicavam que a penetração da marca não passava de $22 \%$ na classe A, 24\% na classe B1, 16\% na classe B2 e apenas 4\% na classe C.

O maior limitante ao aumento de penetração da marca, principalmente nas classes $\mathrm{B}$ e $\mathrm{C}$, era o fato da marca ser associada por esses consumidores a produtos de preços mais elevados. Com o objetivo de conquistar estes usuários, a empresa pretendia reposicionar a marca da empresa como "moda acessível", aumentando a oferta de produtos e intensificando os investimentos em propaganda. Em janeiro de 2007 a empresa lançou a primeira coleção nos moldes da nova estratégia.

A empresa adaptou a sua moda ao seu públicoalvo, adaptando suas estratégias ao mercado. A empresa resgatou a identidade da marca, que era tradicionalmente reconhecida por produtos básicos de qualidade, passou ao púbico mais ligado a produtos de moda, aumentando o seu público de consumidores.

4) A indústria, foco deste caso de ensino, adota um modelo de negócio caracterizado pela: produção; gestão de marcas e produtos; e varejo. Qual o diferencial presente no caso com relação a produção, marcas e varejo?

Produção: A empresa adota um modelo de produção diferenciada, que proporciona optar entre produzir seus produtos de vestuário internamente, terceirização parcial do processo produtivo, ou ainda comprar de terceiros produtos acabados tanto no mercado interno como no externo. A opção entre produzir ou terceirizar é feita com o objetivo de maximizar qualidade, custos e eficiência para atender a demanda do mercado. 
Marcas: A empresa apresenta um portfólio de marcas fortes que apresentam posicionamentos distintos. Suas marcas apresentam o diferencial e os atributos reforçados pela apresentação de 6 coleções anuais, entregues em ciclos a cada duas ou três semanas, garantindo que nas lojas sempre tenha novidades, estimulando a frequência de visitas dos consumidos as lojas. A empresa ainda possui sob seu portfólio quatro marcas que atuam em segmentos de mercados distintos. Os produtos comercializados, para todas as marcas, incluem toda a linha de vestuário e acessórios de moda e básicos para os públicos feminino, masculino e infantil.

Varejo: A empresa atua em 4 canais distintos, (i) o de varejo multimarca; (ii) as franquias; (iii) lojas próprias; (iv) webstore. Em ambos os canais a empresa está crescendo, com ajuda de estudos que analisam o potencial de vendas da empresa. A empresa objetivou aumentar o número de lojas próprias, dentro da rede Store, normalmente lojas-modelo de maior tamanho, em torno de $200 \mathrm{~m} 2$ a $240 \mathrm{~m} 2$. Nas maiores cidades, nas quais a presença da empresa ainda é discreta, é que existe prioridade na abertura, por exemplo, a cidade do Rio de Janeiro, ou shopping centers de alto fluxo, voltados para as Classes A e B. O objetivo de tal estratégia é controlar os pontos de alta visibilidade e fortalecer a construção da marca.

5) A Gestão da Sustentabilidade se tornou importante no processo decisório das organizações, a medida que a sociedade vem se tomando mais consciente e mostrando ser um importante influenciador nas ações que as organizações desenvolvem com relação ao meio ambiente. Quais ações são desenvolvidas pela organização com relação a sustentabilidade organizacional?

No passado, segundo Donaire (1994) o progresso econômico estava atrelado ao aumento exponencial do consumo de recursos, energia, de produção de bens, nos dias atuais esta é uma visão controversa. A questão da saúde do planeta começa a chamar a atenção da sociedade. Segundo Sachs (2000) a sociedade está cada vez mais consciente e preocupada com a capacidade de regeneração do planeta, se preocupando com a agressão ao meio ambiente. A sociedade começa a influenciar as organizações, optando por consumir produtos e serviços de organizações que respeitam o meio ambiente, tornando-se um fator importante no processo decisório das organizações no momento de montar suas estratégias de desenvolvimento.
A empresa analise deste caso de ensino, é consciente sobre a importância da sustentabilidade, tomando decisões estratégicas que busque o desenvolvimento respeitando o meio ambiente. As estratégias relacionadas ao meio ambiente estão focadas na redução do impacto ambiental e melhoria da eficiência operacional nas fábricas e lojas.

Podemos identificar as ações da organização nos seguintes momentos:

- A água utilizada só é

devolvida ao ecossistema após um tratamento biológico e físicoquímico, assim sem causar impactos ambientais.

- Para reduzir a emissão de poluentes na fonte, as caldeiras estão adaptadas para queima de gás natural.

- Os fundadores da organização adquiriram uma extensa área desmatada nas proximidades da fábrica e realizaram o reflorestamento. Esta iniciativa conferiu em 1906, o título de Pioneiro no Reflorestamento no Brasil.

- $\quad$ Atualmente a empresa mantém 8,5 milhões de $\mathrm{m}^{2}$ de áreas verdes conservadas, sendo $750 \mathrm{mil}$ $\mathrm{m}^{2}$ de reserva legal.

- A Política de Gestão Ambiental visa atender à legislação, adotando práticas que minimizem os impactos ambientais da operação. As principais ações são: (i) Comissão Interna de Conservação de Energia (CICE); (ii) Programa de Gestão de Resíduos Sólidos (PGRS); (iii) Certificação FSC (Forest Stewardship Council). 


\section{Bibliografia recomendada}

ALVES, Andre Alexandre; MENEZES, Octaviano M.de S. Cartão de crédito private label: a arma de credito na mão do varejo. NOVATEC. Ed. 1, 2007.

ANSOFF, H. I. Corporate strategy; an analytic approach to business policy for growth and expansion. New York: McGraw-Hill. 1965.

BM\&FBOVESPA. Disponível em: $<$ http://www. bmfbovespa.com.br> Acesso em 02.05.2014

COBRA, M. Marketing e moda. SENAC. Ed 1, 2008.

DOLAN, Robert J.; SIMON, Hermann. O poder dos preços: as melhores estratégias para ter lucro. São Paulo: Futura, 1998.

DONAIRE, D. Considerações sobre a influência da variável ambiental na empresa. Revista de Administração de Empresas, São Paulo, v34, n.2, p.68-77. Mar/Abri. 1994.

DUNNING, J. H; LUNDAN, S. (2009). The internationalization of corporate R\&D: a review of the evidence and some policy implications for home countries. Review of Policy Research, 26(1-2), 1333.

\section{FURRIER, M. T. Posicionamento e}

Reposicionamento de Marcas. In: SERALVO,

F.A. (Org.). Gestão de Marcas no Contexto

Brasileiro. São Paulo: Saraiva, 2008, p. 162-209.

LEENDERS, M. R.; ERSKINE, J. A. Case

Research: The Case Writing Process. London, Ontario: Research and Publications Divisions, School of Business Administration, The University of Western Ontario, 1989.

KOTLER,Philip. Administração de marketing.

São Paulo: Prentice-Hall, 2001.

MACÊDO, Ivanildo Izaias de. Aspectos comportamentais da gestão de pessoas / Ivanildo Izaias de Macêdo, Denize Ferreira Rodrigues, Maria Elizabeth Pupe Johann, Neisa Maria Martins da Cunha. -9 ed. rev. e atual. - Rio de Janeiro : Editora FGV, 2007.

MARRAS, Jean Pierre. Administração de recursos humanos: do operacional ao estratégico / Jean Pierre Marras. - 13 ${ }^{a}$ ed. - SP : Saraiva, 2009.
PARK, Mansoo. The Analysis of Monetary Channel Based on Credit Constraints and the Relative Role of Money and Credit Using VAR Model (The Case of Korea), The Graduate School of Arts and Sciences of the George Washington University, May. 1988

PETERAF, M. A., Barney, J. B. Unraveling the resource-based tangle. Managerial and Decision Economics, 24(4), 309-323. doi: 10.1002/mde.1126. 2003

PORTER, M. E. Competitive advantage: creating and sustaining superior performance. New York: Free Press, Collier Macmillan.1985.

Estratégia competitiva. Técnicas para análise de industrias e da concorrência. Campos. 2004.

POWELL, T. C. Competitive advantage: logical and philosophical considerations. Strategic Management Journal, 22(9), 875-888. doi: 10.1002/smj.173. 2001

RENTES, A. F.; NAZARENO, R. R.; MARDEGAN, R.; JUNQUEIRA, R..P. Lean Production for Enterprises with High Variety of Products. In: FAIM 2005 - International Conference on Flexible Automation and Intelligent Manufacturing, 15., 2005, Bilbao - Spain. Proceedings...

REZENDE, W. Terceirização: A integração acabou? Revista de Administração de empresas. São Paulo, v.37, n.4, p.6-15, 1997.

ROULEAU, L. Micro-Practices of Strategic Sensemaking and Sensegiving: How Middle Managers Interpret and Sell Change Every Day, Journal of Management Studies, 42, 7, 14,13-41. 2005.

RUMELT, R. P; SCHENDEL, D. E; TEECE, D. J. Strategic management and economics. Strategic Management Journal, v. 12, special issue, p. 5-29, 1991.

SACHS, I. Caminhos para o Desenvolvimento Sustentável. Rio de Janeiro: Garamond, 2000.

SARDINHA, José Carlos. Formação de preço: a arte do negócio. São Paulo: McGrawHill, 1995.

STUCKY; John; WHITE, David. When and when not to vertically integrate. Sloan Management Review, v. 34, n. 3, 1993. 
TELLES, Renato; Posicionamento e

reposicionamento de marca: uma perspectiva estratégica e operacional dos desafios e riscos. Tese (Doutorado em Administração) - Programa de Pós-Graduação em Administração, Faculdade de Economia, Administração e Contabilidade da Universidade de São Paulo, São Pulo, 2004.

TOWNSEND, J.D.; CAVUSGIL, S.T.; BABA, M.L. Global integrations of brands and new product development at General Motors. Journal of Product Innovation Management, v.27, n.1, p.4965, 2010.

WANG, D.; XU, C.G Hibrid pusch/pull production control strategy simulation and its applications.

Production Planning and Control, v8, n2, p.142151.

WHITTINGTON, R. Completing the practice turn in strategy research. Organization Studies, 27, 5, 613-634, 2006.

WRIGHT, P.; KROLL, M.J.; PARNELL, J. Strategic Management: Concepts and cases. NJ: PresenticeHall, 1998. 